\title{
IMPORTÂNCIA DO PAINEL DE SCREENING DE IMUNOFENOTIPAGEM POR CITOMETRIA DE FLUXO PARA O DIAGNÓSTICO DE LEUCEMIAS AGUDAS
}

\author{
IMPORTANCE OF THE IMUNOPHENOTYPING SCREENING PANEL \\ BY FLOW CYTOMETRY FOR ACUTE LEUKEMIA DIAGNOSIS
}

Antonielle Arruda de Souza ${ }^{1}$

Fabiane Spagnol Pedrazzani²

\section{RESUMO}

As leucemias agudas compreendem um grupo heterogêneo de neoplasias clonais que diferem quanto à etiologia, patogênese, história natural e prognóstico. A proliferação, nesses casos, está acelerada afetando a produção de células hematopoéticas, ocasionando insuficiência da medula óssea e acometimento extracelular. Classicamente as leucemias dividem-se nas duas principais linhagens leucocitárias: linfóides e mielóides. A imunofenotipagem, realizada pela técnica de citometria de fluxo, é útil tanto no diagnóstico como na classificação, prognóstico, estadiamento e monitoramento das leucemias através da caracterização fenotípica das células hematopoiéticas patológicas. É um método multiparamétrico, que utiliza anticorpos monoclonais marcados com fluorocromos para analisar qualitativa e quantitativamente padrões de expressão de antígenos. $O$ tubo de triagem contendo

\footnotetext{
${ }^{1}$ Pós-Graduando em Análises Clínicas - Universidade do Extremo Sul Catarinense - UNESC, Farmacêutico Generalista - Centro Universitário Facvest. End.: Rua Irmã Laurinda, 165, Centro. Lages SC - Brasil 88501-250. antonielle.souza@hotmail.com

${ }^{2}$ Farmacêutica Bioquímica. Unidade de Diagnóstico Personalizado - Serviço de Patologia Clínica - Hospital de Clínicas de Porto Alegre
} 


\section{Artigo Original}

\section{Fisiopatologia}

8 anticorpos, foi idealizado para uma análise rápida e eficiente de uma amostra, para a identificação, enumeração e caracterização das populações de células suspeitas.

Palavras-chave: Leucemias agudas, Citometria de fluxo, Imunofenotipagem, Painel de triagem.

\section{ABSTRACT}

Acute leukemias consist of a heterogeneous group of clonal neoplasms that differ in etiology, pathogenesis, natural history and prognosis. Proliferation, in these cases, is accelerated affecting the production of hematopoietic cells, causing bone marrow insufficiency and extracellular involvement. Classically, leukemias are divided into the two main leukocyte lines: lymphoid and myeloid. Immunophenotyping, performed by the flow cytometry method, is useful both in the diagnosis and in the classification, prognosis, staging and monitoring of leukemias through the phenotypic characterization of pathological hematopoietic cells. It is a multi-parametric method that uses monoclonal antibodies labeled with fluorochromes to qualitatively and quantitatively analyze antigen expression patterns. The screening tube containing 8 antibodies was designed for rapid and efficient analysis of a sample to identifying, enumerating and characterizing suspect cell populations.

Key words: Acute leukemias, Flow cytometry, Immunophenotyping, Screening panel. 


\section{INTRODUÇÃO}

As leucemias agudas (LAs) compreendem um grupo heterogêneo de neoplasias clonais que diferem quanto à etiologia, patogênese, história natural e prognóstico ${ }^{1}$, caracterizam-se pela proliferação clonal e pelo bloqueio maturativo das células hematopoéticas, com substituição difusa da medula óssea por células neoplásicas ${ }^{2}$. A transformação maligna ocorre nas células imaturas que perdem sua capacidade de maturação e diferenciação, passando a não exercer corretamente suas funções. A proliferação, nesses casos, está acelerada afetando a produção de células hematopoéticas, ocasionando insuficiência da medula óssea e acometimento extracelular ${ }^{3}$.

Classicamente as leucemias dividem-se nas duas principais linhagens leucocitárias: linfóides e mielóides. As células clonais podem apresentar-se indiferenciadas ou pouco diferenciadas, dependendo do grau de maturação no sangue periférico (SP) e/ou na medula óssea $(\mathrm{MO})^{4}$. Durante o processo de diferenciação, ocorrem mudanças nos níveis de expressão de diversas proteínas (antígenos), o que permite estabelecer compartimentos maturativos tanto na linhagem mielóide e linfóide, com padrão e critérios bem estabelecidos ${ }^{5}$.

A imunofenotipagem, realizada pela técnica de citometria de fluxo (CMF), é útil tanto no diagnóstico como na classificação, prognóstico, estadiamento e monitoramento das leucemias através da caracterização fenotípica das células hematopoiéticas patológicas ${ }^{6}$. É um método multiparamétrico, que utiliza anticorpos monoclonais marcados com fluorocromos para analisar qualitativa e quantitativamente padrões de expressão de antígenos (CDs - do inglês, clusters designations) em populações celulares de interesse ${ }^{7}$.

Em relação à microscopia convencional, a CMF apresenta inúmeras vantagens para a análise de células hematopoiéticas, principalmente no que diz respeito às limitações de interpretação e resolução do microscopista. A CMF apresenta alta sensibilidade, especificidade e precisão, permitindo análises multiparamétricas de um grande número de células em pequeno intervalo de tempo ${ }^{8}$.

Uma estratégia na etapa de triagem é uma combinação de anticorpos para a avaliação inicial da natureza das células hematopoiéticas imaturas em amostras com 
suspeita de leucemia aguda. Um tubo único com anticorpos predefinidos que permite a identificação da linhagem celular e orientação adequada prévia a um painel de caracterização completa ${ }^{9}$.

O objetivo do presente estudo é apresentar o tubo de triagem de LAs com os anticorpos para definição da linhagem celular e que posteriormente direciona os painéis destinados a classificar os diferentes tipos de leucemias de acordo com as categorias de doenças definidas pela Organização Mundial de Saúde (OMS).

\section{CLASSIFICAÇÃO DAS LEUCEMIAS}

As leucemias agudas apresentam características morfológicas, clínicas, imunológicas e moleculares distintas e sua classificação precisa é primordial para o tratamento adequado e o seu prognóstico. Inicialmente, em 1976, um grupo cooperativo Franco-Americano-Britânico publicou a classificação denominada FAB, que era essencialmente morfológica e que foi revisada no ano de 1985, tornando-se referência no estudo das leucemias agudas ${ }^{3}$.

A classificação $F A B$ propôs a divisão das $L A$ s nos subtipos $L 1$, L2 e L3 para a LLA-B e para a LMA que inicialmente foram classificadas em tipo M1 (mínima diferenciação), M2 (com maturação), M3 (promielocítica), M4 (mielomonocítica), M5 (monocítica), M6 (eritroleucemia) e M7 (megacarioblástica). Posteriormente foi acrescido o subtipo $\mathrm{M} 0$ (sem maturação). Atualmente, sabe-se que a análise morfológica, mesmo utilizando colorações citoquímicas, torna-se muitas vezes insuficiente para determinar, com exatidão, a linhagem celular sendo incorporados outros métodos diagnósticos como a imunofenotipagem e análise molecular ${ }^{3}$.

Em 2008, a classificação dos tumores hematopoiéticos e tecidos linfóides da Organização Mundial de Saúde, incorporou avanços na compreensão dos aspectos moleculares, genéticos e clínicos das neoplasias hematolinfóides, facilitando o manejo de pacientes, bem como estudos de investigação futuras. A caracterização morfológica e imunofenotípica continuam a serem cruciais para um diagnóstico preciso, bem como monitoramento da resposta à terapia ${ }^{10}$. Um resumo esquemático da classificação da Organização Mundial de Saúde para a leucemia aguda é apresentado no Quadro1. 


\begin{tabular}{|c|}
\hline Leucemia Mieloide Aguda \\
Leucemia Mieloide Aguda (LMA) com anormalidades genéticas \\
recorrentes \\
Leucemia Mieloide Aguda relacionada a transformação de \\
mielodisplasia \\
Leucemia Mieloide Aguda, sem outra classificação específica \\
Sarcoma Mieloide \\
Proliferação Mieloide relacionada com a Síndrome de Down \\
Neoplasia blástica plasmacitoide de células dendríticas \\
Leucemias Agudas de Linhagens Ambíguas \\
Leucemia Aguda não diferenciada \\
Leucemia Aguda de fenótipo misto com t(9;22)(q34;q11.2); \\
BCR-ABL1 \\
Leucemia Aguda de fenótipo misto com t(v;11q23); rearranjo \\
MLL \\
Leucemia Aguda de fenótipo misto, mieloide-B, NOS \\
Leucemia Aguda de fenótipo misto, mieloide-T, NOS \\
Leucemia/Linfoma Linfoblástico B \\
Leucemia/Linfoma Linfoblástico B, NOS \\
Leucemia/Linfoma Linfoblástico B com anormalidades
\end{tabular}

Quadro 1. Classificação da OMS para as Leucemias Agudas ${ }^{10}$.

\section{IMUNOFENOTIPAGEM}

A imunofenotipagem por citometria de fluxo é uma metodologia direcionada, entre outras aplicações, à caracterização fenotípica de células $^{11}$ e revela informações importantes ao diagnóstico, como o estágio de maturação das populações celulares analisadas, a presença de células com fenótipo significativamente anormal, além de avaliar a presença de marcadores associados ao prognóstico ou até mesmo marcadores que são alvos terapêuticos ${ }^{12}$. 
A classificação imunofenotípica das leucemias baseia-se na marcação de células em suspensão incubadas com anticorpos monoclonais (AcMo) conjugados a um fluorocromo. A detecção dessas células ocorre através de emissão das fluorescências através de um citômetro de fluxo. Os sinais fluorescentes são decorrentes da presença dos antígenos de membrana e intracelulares nas células examinadas ${ }^{13}$.

A dinâmica funcional dos citômetros de fluxo é composta principalmente por três sistemas. O sistema fluídico, meio utilizado para transportar as células em suspensão para o interior de uma câmara especial, que através de um fluxo líquido contínuo, alinha as células uma a uma por diferença de pressão, para serem interceptadas por um ou mais feixes de lasers. O sistema ótico, composto por lasers, filtros e espelhos, tem função de incidir luz e direcionar os fótons emitidos pelos fluoróforos e pela dispersão (scatter) da luz de acordo com as características físicas das células. A luz dispersa na linha do feixe retilíneo denominado espalhamento frontal (Forward Scatter - FSC) é equivalente ao volume celular e o feixe perpendicular ou espalhamento lateral (Side Scatter - SSC) está relacionado à complexidade interna da célula, como exemplo, formato nuclear, quantidade e tipo dos grânulos citoplasmáticos e deformidades da membrana. Há também a captação das fluorescências emitidas pelos fluoróforos conjugados aos anticorpos ligados às células que foram excitados pelo(s) laser(s). Todas essas informações são direcionadas através de filtros óticos e espelhos para então serem detectados por fotossensores, os fotodiodos de silício e os tubos fotomultiplicadores (PMTs - do inglês, photomultiplier tubes). Por fim, o sistema eletrônico capta os sinais óticos e os converte em sinais eletrônicos intermediando do sistema analógico para 0 sistema digital, e são direcionados a um software para as análises dos dados ${ }^{14}$.

É possível utilizar diversos tipos de amostras, como exemplo, SP, aspirados de (MO), culturas celulares, entre outras. No primeiro passo do processamento, uma alíquota da amostra é adicionada a um tubo, juntamente com os anticorpos dos antígenos celulares a serem pesquisados, homogeneizada e incubada por 30 minutos a temperatura ambiente para proporcionar a ligação. Amostras de SP e MO são submetidas à lise das hemácias com uma solução lisante, centrifugadas e lavadas com salina tamponada. Por fim, a população de leucócitos marcados é 
ressuspendida em solução salina e as células são adquiridas pelo citômetro de fluxo ${ }^{15}$.

\section{PAINEL DE SCREENING}

A lista de anticorpos clinicamente úteis tem aumentado progressivamente, conduzindo à definição de perfis imunofenotípicos complexos. Em paralelo, o número de antígenos que podem ser avaliados em uma única análise tem aumentado muito devido à disponibilidade de novos instrumentos digitais multicolor e um maior número de fluorocromos compatíveis. Isto facilitou a identificação mais precisa e caracterização fenotípica de populações específicas de leucócitos ${ }^{16}$.

O painel de anticorpos e o volume de amostra contribuem para a decisão sobre a quantidade pipetada de anticorpos a serem usados simultaneamentes e analisados em um único tubo ${ }^{17}$. A disponibilidade de clones ideais de anticorpos conjugados com fluorocromos também determina a seleção de combinações específicas de reagentes em um painel ${ }^{18}$.

A base estratégica da imunofenotipagem tem dados que se fundem $e$ ferramentas de cálculos que são combinados para um melhor diagnóstico e classificação das neoplasias hematológicas, assim foi previsto um requisito mínimo de painéis de 8 cores para imunofenotipagem rentável. Tais painéis devem permitir a utilização simultânea de marcadores destinados à identificação específica das populações de células de interesse e marcadores de anticorpos adicionais para uma caracterização mais detalhada das referidas populações celulares ${ }^{19}$.

O tubo de triagem foi concebido para a avaliação inicial da natureza das populações imaturas de células hematopoiéticas em amostras de leucemia aguda, a fim de permitir a orientação apropriada para o painel de anticorpos complementar. Mais especificamente, o tubo de triagem para LAs (ALOT - do inglês, Acute Leukemia Orientation Tube) contendo 8 anticorpos, foi idealizado para uma análise rápida e eficiente de uma amostra, através da identificação, enumeração e caracterização das populações de células suspeitas quando os dados clínicos e laboratoriais são indicativos de leucemia, como por exemplo, número elevado de glóbulos brancos ou citopenias. Este painel de anticorpos de 8 cores é flexível para 
a identificação e caracterização multidimensional de células normais e anormais, pois são adequados para o rastreio imunofenotípico e classificação de doenças malignas hematológicas ${ }^{20}$. (Quadro 2)

\begin{tabular}{|c|c|c|c|c|c|c|c|c|}
\hline Fluorescência & $\begin{array}{c}\text { Pacific } \\
\text { Bue }\end{array}$ & $\begin{array}{c}\text { Pacific } \\
\text { Orange }\end{array}$ & FITC & PE & $\begin{array}{c}\text { Percp } \\
\text { Cy5.5 }\end{array}$ & $\begin{array}{c}\text { PE- } \\
\text { CY7 }\end{array}$ & APC & $\begin{array}{c}\text { APC- } \\
\text { H7 }\end{array}$ \\
\hline $\begin{array}{c}\text { Anticorpo } \\
\text { Monoclonal }\end{array}$ & cCD3 & CD45 & cMPO & cCD79a & CD34 & CD19 & CD7 & mCD3 \\
\hline
\end{tabular}

Quadro 2: Tubo ALOT - tubo de triagem único contendo 8 anticorpos em cada fluorescência. c: citoplasmático; m: membrana ${ }^{20}$.

$O$ painel deve ser suficientemente abrangente para identificar o tipo de leucemia para as circunstâncias clínicas. Isto não obriga que o painel inicial contenha todos os reagentes necessários para caracterizar completamente todas as possibilidades de diagnóstico, mas que seja capaz de detectar a sua presença com um grau adequado de sensibilidade e sugira estudos adicionais que podem ser realizados para a classificação, prognóstico e diagnóstico definitivo ${ }^{21}$.

Com a amostra contendo células blásticas e definido a linhagem celular mielóide, linfoide T, B ou NK com tubo único (ALOT), complementa-se com um painel multitubos desenvolvidos para a caracterização completa da malignidade. Portanto a escolha do segundo painel depende dos resultados obtidos com o tubo de triagem ${ }^{20}$.

A escolha do segundo painel requer uma seleção cuidadosa de combinações únicas de marcadores individuais com base no seu grau de especificidade para a identificação de uma determinada linhagem celular, estágio de maturação e fenótipo aberrante, assim como a seleção de clones de anticorpos e conjugados de fluorocromos adequados para serem usados em combinações. O desempenho destas combinações de marcadores é ainda mais relevante do que a dos marcadores individuais. Por conseguinte, a seleção cuidadosa dos reagentes é essencial para a concepção de combinações de anticorpos multicolor padronizados que fornecem padrões de coloração únicos para cada população de células normal ou aberrante numa dada amostra 22 . 


\section{IDENTIFICAÇÃO DAS CÉLULAS}

A diferenciação de células hematopoiéticas tem como um padrão específico o CD45, antígeno panleucocitário sendo um importante marcador na identificação das populações de células suspeitas ${ }^{23}$. (Figura 1)
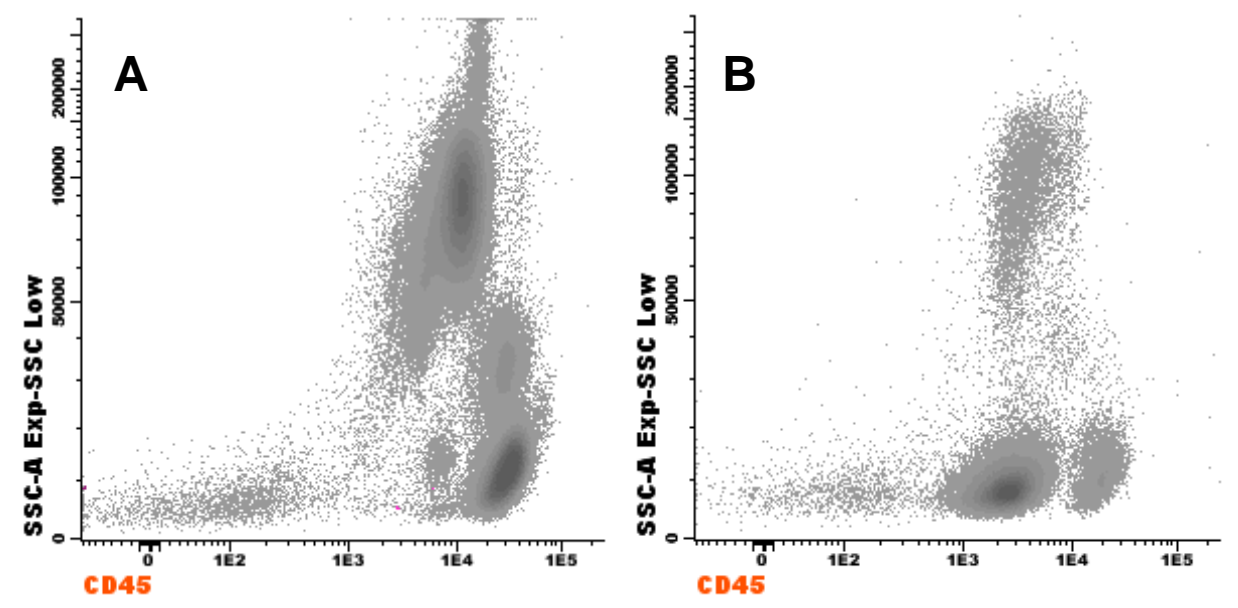

Figura 1: Exemplo do CD45 panleucocitário em amostras normal e patológica. A) Amostra de MO normal, com todos os leucócitos positivos e distinguidos pela granulosidade (SSC) apresentada pelas células. B) Presença de uma população clonal imatura na região do CD45 fraco e com baixa complexidade.

Para refinar a seleção e confirmar ainda mais a natureza da população imatura, o CD34 é selecionado, pois é o primeiro marcador a se expressar em células progenitoras hematopoiéticas humanas, uni e multipotentes. Está presente em $1 \%$ a $2 \%$ das células normais da $\mathrm{MO}$, em mais de $90 \%$ das células hematopoiéticas imaturas e vai perdendo com a maturação celular. Este marcador está presente em 60\% das leucemias linfóides e mielóides agudas ${ }^{24}$. (Figura 2) 

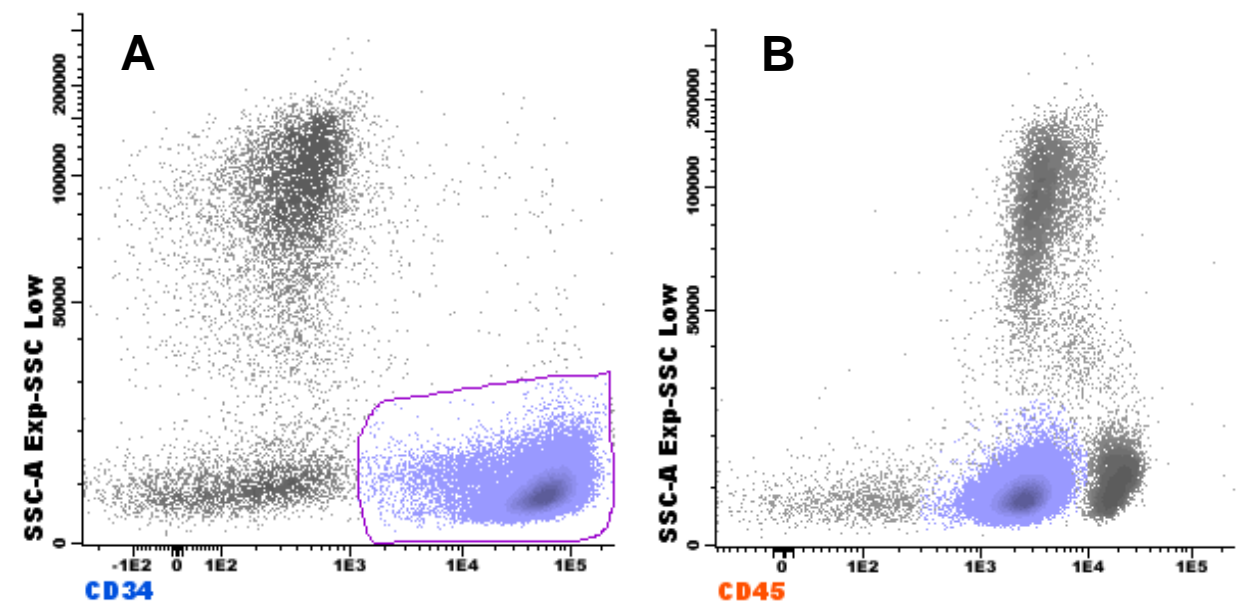

Figura 2: A) Seleção da população CD34 positiva. B) Identificação simultânea da população clonal imatura na região do CD45 fraco e com baixa complexidade.

A mieloperoxidase (MPO) reage com granulócitos e monócitos no SP e na MO a MPO identifica leucemia mielóide através do percentual de blastos positivos. Casos M1, M2, M3, M4 e alguns casos de M5 (classificação FAB) são MPO positivos $^{25}$. (Figura 3 )
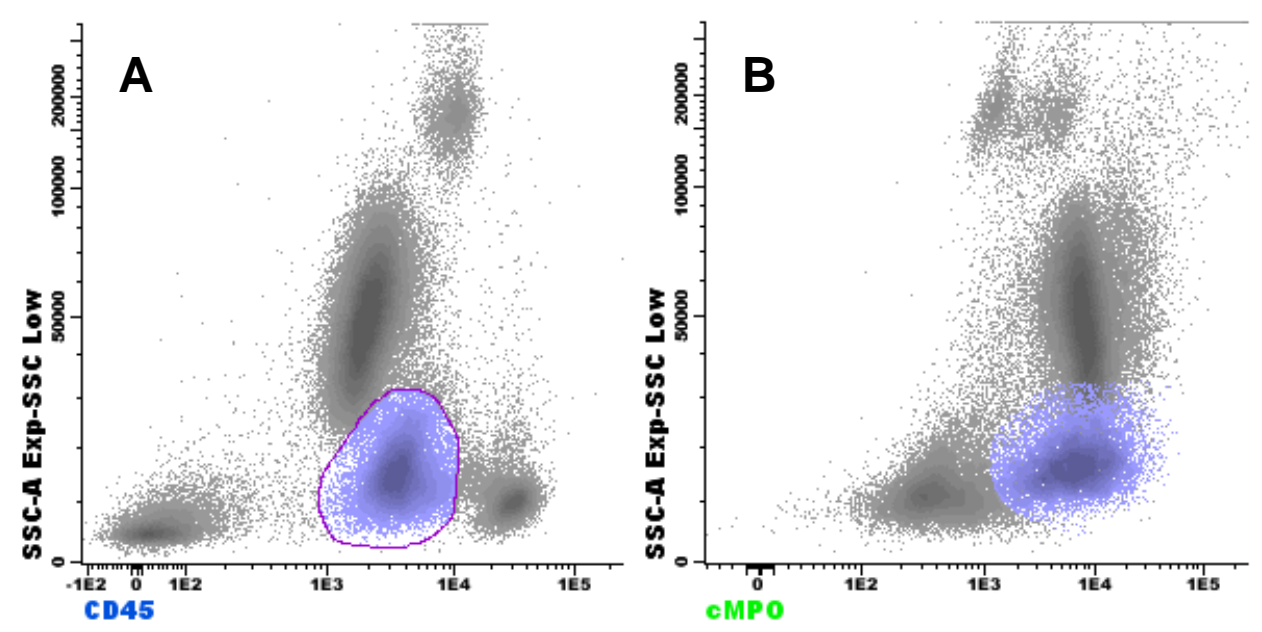

Figura 3: A) Seleção da população clonal imatura na região do CD45 fraco e com baixa complexidade. B) Identificação simultânea da expressão de MPO citoplasmático nesta população.

O CD3 citoplasmático ( $C C D 3$ ) é um marcador de linhagem T específico, que deve ser interpretado em combinação com o CD3 de membrana (mCD3), a fim de identificar as células $\mathrm{T}$ imaturas $\left(\mathrm{cCD}^{+} / \mathrm{mCD}^{-}\right)$, o fenótipo mais frequente no Linfoma Linfoblástico $\mathrm{T}^{20}$. (Figura 4) 


\section{Fisiopatologia}
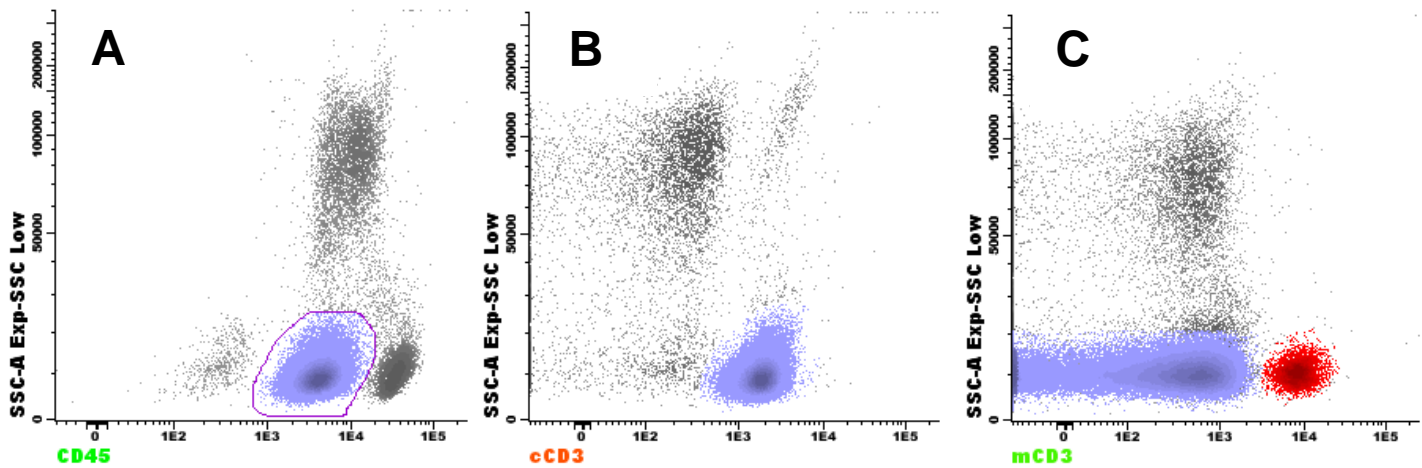

Figura 4: A) Seleção da população clonal imatura na região do CD45 fraco e com baixa complexidade. B) Identificação simultânea da expressão de CD3 citoplasmático da população clonal. C) expressão negativa de CD3 de membrana na população clonal. Em vermelho as células T maduras positivas para CD3.

O CD19 foi selecionado como um marcador de linhagem B muito sensível, que é expresso durante as fases iniciais do comprometimento das células $B$. No entanto, o CD19 é pouco específico, uma vez que também é expresso em subtipos de casos de LMA como coexpressão, embora em níveis mais baixos e mais heterogéneos. Consequentemente, CD79a citoplasmático melhora a atribuição da linhagem $B$, pois está em vários estágios de diferenciação de célula $B$, é detectado somente no citoplasma e um importante marcador de LLA-B precoce ${ }^{26}$. (Figura 5)
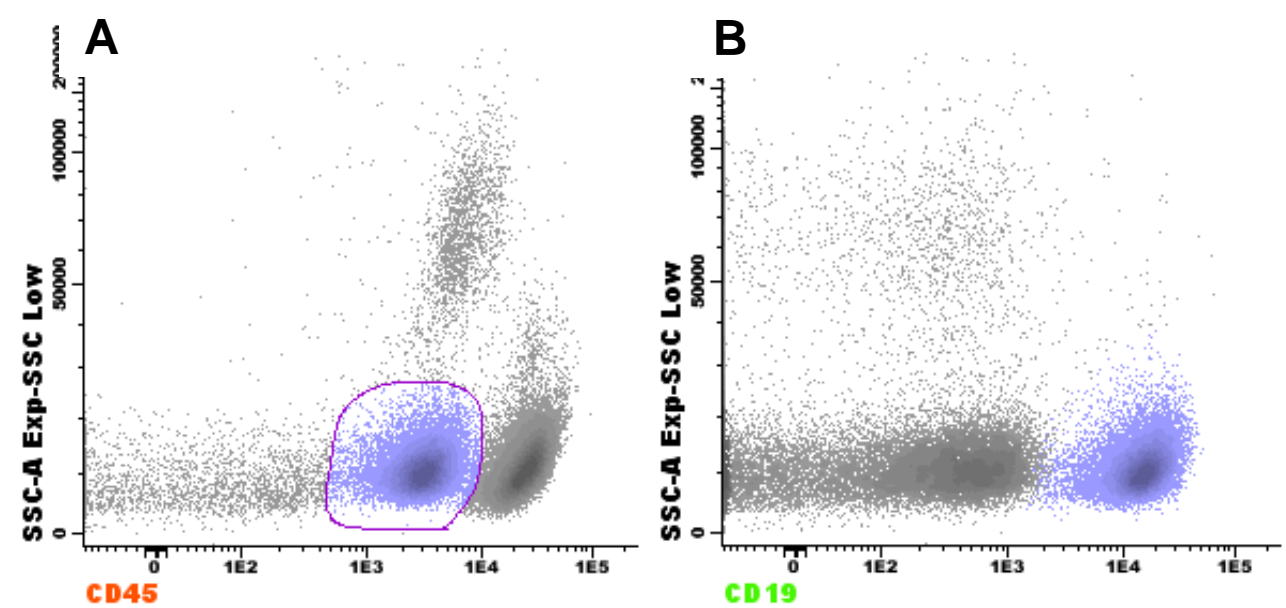

Figura 5: A) Seleção da população clonal imatura na região do CD45 fraco e com baixa complexidade. B) Identificação simultânea da expressão de CD19 nesta população.

O CD7 foi selecionado, pois acredita-se que é o primeiro antígeno associado à linhagem $\mathrm{T}$, sendo positivo em praticamente todos os casos de Linfoma 


\section{Fisiopatologia}

Limfoblástico T. Está fortemente presente na maioria das células precursoras da leucemia linfoblástica aguda, mas é consistentemente negativo em células B. CD7 distingue precursores de $T$ e $B$ na LLA e se expressa em pequena proporção em LMA, especialmente M4 e M5527. (Figura 6)
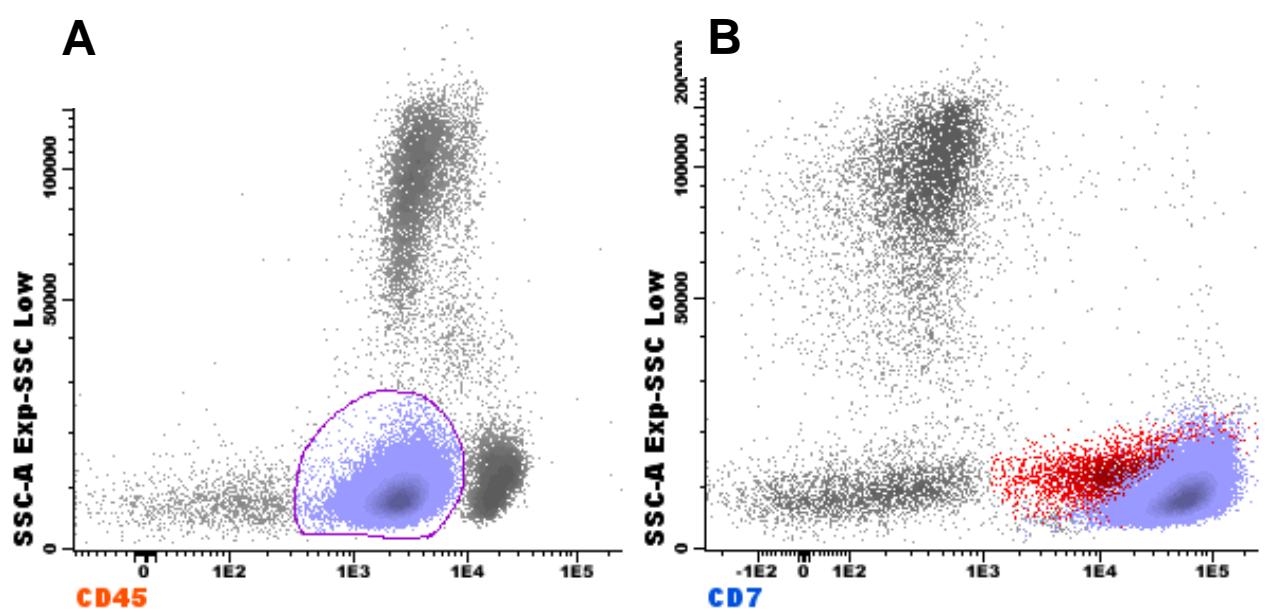

Figura 6: A) Seleção da população clonal imatura na região do CD45 fraco e com baixa complexidade. B) Identificação simultânea da expressão de CD7 da população clonal. Em vermelho as células T maduras positivas para CD7.

Uma relação dos anticorpos, fluorocromos e especificidade é apresentada no quadro 3.

\begin{tabular}{|l|l|l|}
\hline Anticorpo & \multicolumn{1}{|c|}{ Fluorocromo } & \multicolumn{1}{c|}{ Especificidade } \\
\hline CD45 & OC515 & $\begin{array}{l}\text { Leucócitos humanos, incluindo linfócitos, } \\
\text { monócitos, granulócitos e eosinófilos. }\end{array}$ \\
\hline CD34 & PerCP- Cyanine5.5 & $\begin{array}{l}\text { Precursores hematopoiéticos; Expresso nos } \\
\text { blastos da maioria das leucemias agudas de } \\
\text { qualquer linhagem. }\end{array}$ \\
\hline cMPO & FITC & $\begin{array}{l}\text { Linhagem mielóide na fase inicial da maturação } \\
\text { onde as células estão se diferenciando }\end{array}$ \\
\hline CCD3 & Pacific Blue TM & $\begin{array}{l}\text { Fases iniciais de maturação das células T. } \\
\text { Superfície dos timócitos maduros e células T no } \\
\text { sangue periférico. }\end{array}$ \\
\hline mCD3 & APC-C750 & \multicolumn{2}{|l}{} \\
\hline
\end{tabular}




\section{Fisiopatologia}

\begin{tabular}{|l|l|l|}
\hline CD19 & PE-Cyanine7 & $\begin{array}{l}\text { Superfície de células B, ambos em células } \\
\text { normais ou fases iniciais leucêmicas. É positivo } \\
\text { em quase todos os casos de leucemia } \\
\text { linfoblástica B. }\end{array}$ \\
\hline cCD79a & PE & $\begin{array}{l}\text { Linhagem B, mas também pode ser expresso em } \\
\text { algumas leucemias de diferentes linhagens } \\
\text { celulares, como LMA e linfoma linfoblástico T. }\end{array}$ \\
\hline CD7 & APC & $\begin{array}{l}\text { Linhagem linfóide T e NK mas também é } \\
\text { expresso em LMAs. }\end{array}$ \\
\hline
\end{tabular}

Quadro 3. Relação Anticorpo, fluorocromo e especificidade $\overline{20}$.

\section{DESEMPENHO DOS ANTICORPOS}

Muito mais do que a enumeração dos blastos, a identificação fenotípica destas células por CMF apresenta um papel central no diagnóstico das doenças blásticas. O estabelecimento da CMF para diferenciar leucemia linfoblástica aguda (LLA) de leucemia mieloide aguda (LMA) e definir a terapêutica apropriada representou um grande avanço no diagnóstico por ser um método bastante reprodutível para este fim específico ${ }^{28}$.

Uma vez que as células anormais foram identificadas e seu fenótipo descrito, é então necessário reunir as informações fenotípicas e fazer uma interpretação. A interpretação de dados de citometria de fluxo não é baseada na aplicação rígida de regras imunofenotípicas para diagnóstico ${ }^{29}$.

A avaliação do desempenho de um determinado anticorpo conjugado pode ser baseada em medidas absolutas (por exemplo, intensidade de fluorescência obtido para uma dada população de células de controle) ${ }^{30}$, no entanto este parâmetro pode não ser aplicado uma vez que o marcador é combinado com outros reagentes em um tubo único ou em um painel de anticorpos multitubos. Portanto, cada reagente tem de ser avaliado quanto ao seu padrão de coloração única obtida para as populações de células distintas num espaço multidimensional definido por todos os parâmetros do tubo multicolor recentemente concebido. Por conseguinte, a 
avaliação dos perfis imunofenotípicos de populações celulares de leucemia devem preferencialmente ser baseada numa comparação detalhada dos fenótipos de células individuais para todos os marcadores em conjunto, ao em vez da interpretação subjetiva dos níveis de fluorescência média arbitrários (por exemplo: negativo vs positivo, fraca vs forte, homogênea em relação padrões heterogêneos) de uma lista de marcadores individuais. Visualização de tais espaços multidimensionais e seleção dos parâmetros importantes para a discriminação ótima entre as populações de células relevantes exigem novas ferramentas de softwares. Essas ferramentas provam ser essenciais para a avaliação crítica no desenho das combinações de anticorpos. Entre as ferramentas, arquivos de dados de referência de entidades normais e distintas da doença foram construídos os painéis avaliados através de comparações estatísticas de arquivos de dados normais versus de doenças específicas, bem como de arquivos de dados correspondentes a entidades leucêmicas. Desta forma, pode-se avaliar objetivamente o desempenho geral dos painéis propostos para responder as perguntas clínicas específicas ${ }^{31}$.

\section{CONDUTAS CLÍNICAS E FATORES PROGNÓSTICOS}

A identificação da doença em seu estágio inicial e o encaminhamento ágil e adequado para o atendimento especializado dão à Atenção Básica um caráter essencial para um melhor resultado terapêutico e prognóstico dos casos ${ }^{32}$.

A cura é uma meta realizável, tanto na LLA como na LMA, especialmente em pacientes mais jovens. O primeiro objetivo é conseguir a remissão completa, com resolução de características clínicas anormais, retorno a contagens sanguíneas e hematopoiese normais na $\mathrm{MO}$ e desaparecimento de clone leucêmico. A terapia específica está sendo constantemente melhorada ${ }^{33}$.

Para o tratamento das LLAs vários esquemas enfatizam a introdução precoce de um esquema intensivo de multidrogas. $\mathrm{Na}$ fase de indução a principal finalidade, é induzir uma remissão completa, que é geralmente definida pela redução dos blastos leucêmicos e restaurar a hematopoese normal, em um período o mais curto possível, em geral de quatro a seis semanas ${ }^{33}$. 
Na LLA B, os fármacos utilizados são a prednisona e a vincristina, pois atuam rapidamente, apresentam atividade antileucêmica sinérgica, sem toxicidade aditiva e não interferem em grau significativo com a regeneração da hematopoese, aspecto essencial da remissão completa $^{34}$. Os fatores prognósticos favoráveis para esta patologia incluem a idade de 3 a 7 anos, um cariótipo com mais de 50 cromossomos, a translocação $(12 ; 21)$ e sem doença do SNC no diagnóstico. Os fatores desfavoráveis são um cariótipo normal em número, presença da translocação (9:22), morfologia anormal (pseudiplóides), aumento de idade em adultos e imunofenótipo de célula B com imunoglobulina citoplasmática ou de superfície ${ }^{33}$.

De acordo com o Consenso Internacional, publicado em 1996, pacientes com LLA B com menos de 50.000 leucócitos $/ \mathrm{mm}^{3}$ ao diagnóstico, por apresentarem melhor prognóstico, devem ser incluídos dentro do grupo de Risco Básico, enquanto que aqueles com leucometria superior são classificados como Alto Risco e, portanto, devem ser submetidos a tratamento mais intensivo ${ }^{35}$.

O tratamento da LLA T é baseado em esquema de quimioterapia, levando-se em consideração as características clínicas, imunológicas, citogenéticas e o envolvimento ou não de outros órgãos para a escolha do protocolo mais adequado. Por vezes não é possível diminuir a sobrevida livre de doença, sendo o transplante de células-tronco hematopoiéticas (TCTH) uma boa opção terapêutica na consolidação da remissão ${ }^{36}$.

Portanto a imunofenotipagem nas LLAs é mandatória para a definição da origem celular $\mathrm{T}$ ou $\mathrm{B}$, além de identificar os subtipos imunofenotípicos, que são de relevância no prognóstico e no tratamento dos pacientes ${ }^{37}$.

As características prognósticas das LMAs mais importantes são a idade, fase mielodisplásica precedente, leucemia secundária, cariótipo celular leucêmico, contagem de leucócitos e presença de bastonetes de Auer. A classificação FAB isoladamente não prediz a resposta ${ }^{33}$.

Com a melhora do tratamento da LMA, e consequente maior tempo de seguimento clínico houve reconhecimento de alguns subtipos de LMA com melhor resposta terapêutica e maior tempo de sobrevida. Estes subtipos de LMA possuem 
características citogenéticas e imunofenotípicas especiais, importantes na prática clínica ${ }^{38}$.

O tratamento da LMA exige uma quimioterapia inicial de indução com o objetivo de atingir remissão completa da doença e consequente restauração das células sanguíneas normais. Após, é seguida por uma terapia de pós-remissão para erradicar a doença residual, fase de "consolidação" e a fase de "manutenção". Os pacientes com mais de 50 anos são menos prováveis de conseguir a remissão. A incapacidade de atingir a remissão pode se relacionar a óbito ou a resistência a drogas decorrente de infecção ou sangramento durante o período de hipoplasia. Geralmente, o tratamento resulta em mielossupressão significativa; assim, quase sempre por períodos prolongados, clinicamente antes da recuperação da MO. Durante este período, é vital o cuidado preventivo e de suporte ${ }^{33}$.

A cura da LMA ocorre ainda numa minoria de pacientes adultos que se submetem aos diversos protocolos de quimioterapia e, nos casos de prognóstico intermediário ou desfavorável, apesar do elevado potencial de morbidade, os resultados do transplante de células-tronco hematopoéticas alogênico ou autólogo são melhores do que os obtidos com a quimioterapia padrão ${ }^{32}$.

\section{CONCLUSÃO}

A caracterização das leucemias por imunofenotipagem é mandatória particularmente quando a morfologia é de difícil interpretação, permitindo a identificação da linhagem e dos subtipos particulares de leucemias não reconhecidos pelos critérios morfológicos, que podem ter significância prognóstica ${ }^{39}$.

A imunofenotipagem por citometria de fluxo tem papel fundamental no diagnóstico das Leucemias, uma vez que permite elucidar - de forma rápida e inequívoca - as três principais questões que se impõem frente a um paciente com suspeita clínica de leucemia, quais sejam:

1 - Se a população de células predominante na amostra é normal ou anômala;

2 - Se for anômala, a qual linhagem pertence (linfoide ou mielóide; se linfóide, B, T ou NK);

3 - Se as células anômalas são imaturas ou maduras ${ }^{39}$. 
A identificação específica de células leucêmicas por seleção de população, forma a base para o diagnóstico imunofenotípico, classificação, bem como avaliação prognóstica de pacientes com leucemias agudas. O desempenho do processo em relação aos painéis de reagentes e os processos analíticos é necessariamente diferente em leucemias linfoblásticas e mieloblásticas ${ }^{40}$.

Além disso, em adição ao seu papel no diagnóstico, a imunofenotipagem pode dar outra grande contribuição: a avaliação da doença residual mínima, que permite avaliar a resposta ao tratamento por meio de ensaios de elevadíssima sensibilidade, cujo emprego sistemático nos estudos clínicos tem dado origem a novas estratégias terapêuticas que visam adaptar a intensidade do tratamento ao grau de risco de recidiva da doença ${ }^{11}$.

O objetivo principal de qualquer painel de reagentes utilizado para a avaliação da amostra deve ser suficiente para detectar a presença ou ausência de leucemia aguda, e que o painel deve ser tão eficiente quanto razoavelmente possível para fornecer a caracterização completa da patologia ${ }^{21}$.

Em resposta a clara necessidade de uma abordagem mais eficiente $\mathrm{e}$ padronizada para classificar doenças malignas hematológicas, estudos realizados para validar combinações de anticorpos multicolor, resultaram no tubo de triagem inicial para amostras suspeitas de leucemia que contém combinações de 8 anticorpos pré-selecionados permitindo a orientação apropriada para uma linhagem leucêmica com precisão e eficiência. Possui procedimentos operacionais padronizados otimizados para a integração na citometria de fluxo. Desta forma propõe-se um único tubo, extensivamente testado, para orientação rápida e eficiente de leucemias agudas ${ }^{20}$.

\section{Referencias}

1 - Chang $\mathrm{H}$ et al. Prognostic relevance of immunophenotyping in 379 patients with acute myeloid leukemia. Leukemia Research 28 (2004) 43-48.

2 - Diagnóstico laboratorial das leucemias mielóides agudas. Graziele C. da Silva; Diogo A. Pilger ; Simone M. de Castr3; Sandrine C. Wagner. 2006. 
3 - Silva AM; Neto LMR; Santos, PCJL. Hematologia: métodos e interpretação. São Paulo: Roca, 2013.

4 - Pilger DA; Fernandes F; Silva FC. Imunofenotipagem das leucemias agudas. 2004.

5 - 8- Hrusak O, MacDonald AP. Antigen expression. Patterns refecting genotype of acute leukemias. Leukemia 2002; 16:1233-58.

6 - Bonjean B, Grollet L, Visentin E, Sigaux F, Cayuela JM. Development of a new strategy for minimal residual disease monitoring in children with B-precursor acute lymphoblastic. Ann Biol Clin 62(4):465-70, 2004.

7 - Harris N L, Jaffe E S, Diebold J, FlandrimG, Muller-Hermelink H K, Vardiman J, Lister TA, Bloomfield CD. WorldHealth Organization Classification of Neoplastic Diseases of Hematopoietic and Lymphoid Tissues: Report of the Clinical Advisory Committee Meeting. J. Clin. Oncol. 17(12): 3835-3849, 1999.

8 - Orfao A, Schmitz G, BrandoB, Ruiz-Arguelles A, BassoG, Braylan, R, Rothe G, Lacombe F, Lanza F, Papa S, Lucio P. Clinically Useful Information Provided by the Flow Cytometric Immunophenotyping of Hematological Malignancies: Current Status and Future Directions. Clin. Chem., 45(10): 1708-1717, 1999.

9 - Costa ES, Arroyo ME, Pedreira CE, Garcia-Marcos MA, Tabernero MD, Almeida J et al. A new automated flow cytometry data analysis approach for the diagnostic screening of neoplastic B-cell disorders in peripheral blood samples with absolute lymphocytosis. Leukemia 2006; 20: 1221-1230.

10 - Swerdlow SH, Campo E, Harris NL, et al, eds. Tumours of Haematopoietic and Lymphoid Tissues. 4th ed. Lyon, France: IARC Press; 2008. World Health Organization Classification of Tumours; vol 2.

11 - Duarte AJS; Sales MM; Vasconcelos DM. Citometria de Fluxo Aplicações no Laboratório Clínico e de Pesquisa. Rio de Janeiro: Atheneu. 2013.

12 - Rego, EM; Santos, GAS. Papel da imunofenotipagem por citometria de fluxo no diagnóstico diferencial das pancitopenias e das linfocitoses. 2009.

13 - Ahluwalia, M.S.; Paul, K.; David M.P. Flow cytometry as a diagnostic tool in lymphomatous or leukemic meningitis. Cancer, Vol.118, p. 1747-1753, April 2012.

14 - Teva, A.; Fernandez, J. C. C.; Silva, V. L. Imunologia. In: Molinaro, E. M.; Caputo, L. F. G.; Amendoeira, M. R. R. (Eds.) Conceitos e Métodos para formação 
de profissionais em laboratórios de saúde. 1 ed. Rio de Janeiro: Instituto Oswaldo Cruz, p.1-124, 2009.

15 - John M. Peters, MD, PhD; M. Qasim Ansari, MD. Multiparameter Flow Cytometry in the Diagnosis and Management of Acute Leukemia. 2011.

16 - Craig FE, Foon KA. Flow cytometric immunophenotyping for hematologic neoplasms. Blood 2008; 111: 3941-3967.

17 - Wood B. 9-color and 10-color flow cytometry in the clinical laboratory. Arch Pathol Lab Med 2006; 130: 680-690.

18 - McLaughlin BE, Baumgarth N, Bigos M, Roederer M, De Rosa SC, Altman JD et al. Nine-color flow cytometry for accurate measurement of $T$ cell subsets and cytokine responses. Part I: Panel design by an empiric approach. Cytometry A 2008; 73: 400-410.

19 - T Kalina, J Flores-Montero, V H J van der Velden, M Martin-Ayuso, S Böttcher5, M Ritgen, J Almeida, L Lhermitte, V Asnafi, A Mendonça, R de Tute, M Cullen, L Sedek, M B Vidriales, J J Pérez, J G te Marvelde, E Mejstrikova, O Hrusak, T Szczepański, J J M van Dongen and A Orfao. EuroFlow standardization of flow cytometer instrument settings and immunophenotyping protocols. Leukemia (2012) 26, 1986-2010.

20 - Van Dongen JJM, L'hermitte L, Böttcher S, Almeida J, van der Velden VHJ, Flores-Montero J, Rawstron A, Asnafi V, Lécrevisse Q, Lucio P, Mejstrikova E, Szczepañski T, Kalina T, de Tute R, Brüggemann M, Sedek L, Cullen M, Langerak AW, Mendonca A, Macintyre E, Martin-Ayuso M, Hrusak O, Vidriales MB and Orfao A. EuroFlow antibody panels for standardized n-dimensional flow cytometric immunophenotyping of normal, reactive and malignant leukocytes. Leukemia, 2012, 26(9):1908-1975.

21 - Brent L. Wood, Maria Arroz, David Barnett, Joseph DiGiuseppe, Bruce Greig, Steven J. Kussick, Teri Oldaker, Mark Shenkin, Elizabeth Stone, Paul Wallace. 2006 Bethesda International Consensus recommendations on the immunophenotypic analysis of hematolymphoid neoplasia by flow cytometry: Optimal reagents and reporting for the flow cytometric diagnosis of hematopoietic neoplasia. 2007.

22 - Paietta E. How to optimize multiparameter flow cytometry for leukaemia/lymphoma diagnosis. Best Pract Res Clin Haematol. 2003;16:671-683. 
23 - Vial JP, Lacombe F. Immunophenotyping of acute leukemia: utility of CD45 for blast cell identification. Methods Cell Biol. 2001;64:343-358.

24 - Kita K, Nakase K, Miwa H, Masuya M, Nishii K, Morita N, et al. Phenotypical characteristics of acute myelocytic leukemia associated with the $t(8 ; 21)(q 22 ; q 22)$ chromosomal abnormality: frequent expression of immature B-cell antigen CD19 together with stem cell antigen CD34. Blood. 1992;80:470-477.

25 - S.L.R. Martins, R.P. Falcão. A importância da imunofenotipagem na Leucemia Mielóide Aguda. 2000.

26 - Bhargava P, Kallakury BV, Ross JS, Azumi N, Bagg A. CD79a is heterogeneously expressed in neoplastic and normal myeloid precursors and megakaryocytes in an antibody clone-dependent manner. Am $\mathrm{J}$ Clin Pathol. 2007;128:306-313.

27 - Martin-Martin L, Almeida J, Hernandez-Campo PM, Sanchez ML, Lecrevisse Q, Orfao A. Immunophenotypical morphologic, and functional characterization of maturation-associated plasmacytoid dendritic cell subsets in normal adult human bone marrow. Transfusion. 2009;49:1692-1708.

28 - Newell JO, Cessna MH, Greenwood J, Hartung L, Bahler DW. Importance of CD117 in the evaluation of acute leukemias by flow cytometry. Cytometry B Clin Cytom. 2003;52(1):40-3.

29 - U.S.-Canadian Consensus Recommendations on thelmmunophenotypic Analysis of Hematologic Neoplasiaby Flow Cytometry: Data Analysis and Interpretation. Michael J. Borowitz, Robert Bray, Randy Gascoyne, Steven Melnick, John W. Parker, Louis Picker, Maryalice Stetler-Stevenson. Cytometry (Communications in Clinical Cytometry) 30:236 -244 (1997).

30 - Maecker HT, Frey T, Nomura LE, Trotter J. Selecting fluorochrome conjugates for maximum sensitivity. Cytometry A. 2004;62:169-173.

31 - Pedreira CE, Costa ES, Barrena S, Lecrevisse Q, Almeida J, van Dongen JJ, et al. Generation of flow cytometry data files with a potentially infinite number of dimensions. Cytometry A. 2008;73:834-846.

32 - PORTARIA № 705, DE 12 DE AGOSTO DE 2014

33 - Manual Merck - Diagnóstico e tratamento. Merck, H. B. \& Berkow, R. São Paulo.17ª edição. Edição Centenária. Editora Roco. 2000. 
34 - Appelbaun, F.R. As Leucemias Agudas. In: Bennett; Plum. Cecil Tratado de Medicina Interna. Rio de Janeiro: Guanabara Koogan, 1997. Cap.143, p.1034-1040. 35 - Smith M, Arthur D, Camitta B, Carroll AJ, Crist W, Gaynon P, Gelber R, Heerema N, Korn EL, Link M, Murphy S, Pui CH, Pullen J, Reamon G, Sallan SE, Sather $\mathrm{H}$, Shuster J, Simon R, Trigg M, Tubergen D, Uckun F, Ungerleider R. Uniform approach to risk classification and treatment assignment for children with acute lymphoblastic leukemia. J Clin Oncol. 1996; 14: 4-6. 36 - Lamego, R.M. et al. Transplante alogênico de células-tronco hematopoiéticas em leucemias agudas: a experiência de dez anos do Hospital das Clínicas da UFMG. Rev Bras Hematol Hemoter. 2010:32(2):108-115.

37 - Chauffaille, Maria de Lourdes L. F.; Yamamoto, Mihoko. Classificação das leucemias agudas. 2009.

38 - Creutzig $U$, Harbott $J$, Sperling $C$ et al. Clinical significance of surface antigen expression in children with acute myeloid leukemia. Blood 1995; 86: 3097-3108.

39 - Drexler, H.G. ; Gignac, S.M. ; Minowada, J. Routine immunophenotyping of acute leukemias. Annals of Hematology, vol.57, n6, p.327-339, 1988.

40 - G Basso, B Buldini, L De Zen, A Orfao. New Methodologic Approaches For Immunophenotyping Acute Leukemias. Haematologica January 2001 86: 675-692. 